\title{
EVALUASI PENYIMPANAN OBAT DAN ALAT KESEHATAN DI APOTEK RESTU FARMA
}

\author{
Muhammad Afqary ${ }^{*}$, Febi Ishfahani ${ }^{1}$, M. Tirta Rachman Mahieu ${ }^{1}$ \\ 1.Program Studi Farmasi Sekolah Tinggi Teknologi Industri dan Farmasi Bogor \\ Korespondensi :afqary@gmail.com
}

\begin{abstract}
ABSTRAK
Penyimpanan merupakan salah satu proses penting pada pengelolaan obat dan alat kesehatan. Penyimpanan adalah suatu kegiatan menyimpan dan memelihara dengan cara menempatkan obat obatan yang diterima pada tempat yang dinilai aman dari pencurian serta gangguan fisik yang dapat merusak mutu obat. Penelitian ini bertujuan untuk mengevaluasi sistem penyimpanan obat dan alat kesehatan yang berada di Apotek Restu Farma.Penelitian ini adalah penelitian deskriptif yang membahas penyimpanan obat dan alat kesehatan di Apotek Restu Farma.Penelitian dilakukan dengan pengamatan langsung dan wawancara.Hasil penelitian menunjukkan penyimpanan obat dan alat kesehatan di Apotek Restu Farma di pelayanan dipisahkan berdasarkan bentuk sediaan (tablet, sirup, infus, dan injeksi) serta khasiatnya.Demikian juga penyimpanan obat dan alat kesehatan di gudang, dipisahkan berdasarkan bentuk sediaan (tablet, sirup, infus, dan injeksi). Penyimpanan di ruang pelayanan mencapai persentase $85 \%$ dan gudang $75 \%$ sehingga sudah sesuai dengan Permenkes No. 73 Tahun 2016 tentang standar pelayanan kefarmasian di Apotek
\end{abstract}

\section{Kata Kunci: Apotek, Gudang, Penyimpanan Alat Kesehatan, Penyimpanan Obat}

\section{ABSTRACT}

Storage is one of important process in the management of drug and medical devices. This study aims to evaluate the storage system of drug and medical devices in the Restu Farma Pharmacy. This is a descriptive research which carried on by direct observation and interview. This research was evaluate arrangement of drugs and medical devices in Restu Farma Pharmacy. This research show that in Restu Pharma Pharmacy the drug and medical devices were arranged by type of drugs (tablets, syrups, intervereous liquid and injection). The Restu Pharma Pharamcy"s warehouse was as the drug and medical devices in Restu Pharma Pharmacy ware house was arrange by type of drugs (tablets, syrups, intervereous liquid and injection). The storage in the warehouse at $75 \%$ and the service room at $85 \%$ is [compliance with Permenkes No. 73 of the years 2016 about standard of pharmaceutical care at pharmacy.]

Keyword : Drug Storage, Medical Instrument Storage, Pharmacy, Warehouse 


\section{PENDAHULUAN}

Di era mobilitas seperti ini kesehatan menjadi kebutuhan yang utama, setiap orang mempunyai hak untuk hidup layak, baik kesehatan untuk diri maupun keluarganya. Oleh karena itu usaha untuk meningkatkan kualitas pelayanan di apotek semakin membaik. Berkembangnya pelayanan di Apotek ditunjang oleh sarana dan prasarana yang baik sehingga pelayanan kepada pasien dapat dirasakan secara maksimal dan dapat memudahkan semua orang.

Kegiatan pelayanan kefarmasian didukung oleh pekerjaan kefarmasian yang handal dan professional. Pekerjaan kefarmasian meliputi pembuatan termasuk pengendalian mutu sediaan farmasi, pengadaaan, penyimpanan, pendistribusian atau penyaluarn obat, pengelolaan obat, pelayanan obat atas resep dokter, pelayanan informasi obat, serta pengembangan obat, bahan obat atau obat tradisional (Peraturan Pemerintah No. 51 Tahun 2009).

Salah satu hal yang penting bagi terselenggaranya kegiatan pekerjaan kefarmasian adalah pengelolaan obat. Pengelolaan obat di Apotek meliputi perencanaan, pengadaan, penerimaan, penyimpanan, pendistribusian, pencatatan dan pelaporan serta pemusnahan. Penyimpanan merupakan kegiatan menyimpan dan memelihara mutu sediaan farmasi serta memudahkan pencarian dan pengawasan obat. Menurut Peraturan Menteri Kesehatan Nomor

30 Tahun 2014 tentang kefarmasian di Puskesmas, penyimpanan adalah suatu kegiatan menyimpan dan memelihara dengan cara menempatkan obat-obatan yang diterima pada tempat yang dinilai aman dari pencurian serta gangguan fisik yang dapat merusak mutu obat.

Menurut penelitian yang dilakukan oleh Puslitbang Biomedis dan Farmasi (2006) diketahui bahwa masih banyak gudang penyimpanan obat di puskesmas dan rumah sakit di Indonesia yang kurang memenuhi persyaratan seperti tidak menggunakan sistem alfabetis dalam penataannya, tidak menggunakan sistem FIFO (First In First Out) atau FEFO (First Expired First Out) dan penggunaan kartu stok yang belum memadai.

Berdasarkan uraian di atas, penulis tertarik untuk melakukan penelitian di Apotek Restu Farma yang berada di .Jl. Raya Leuwiliang No.21 A Pasar Lama Ds. Leuwiliang, Kec.Leuwiliang. Kab Bogor, untuk mengetahui penyimpanan di Apotek Restu Farma apakah sesuai dengan tata cara penyimpanan Obat dan Alat Kesehatan di Apotek sudah diatur dalam Peraturan Menteri Kesehatan Nomor 73 Tahun 2016.

\section{Penyimpanan Obat}

Menurut Peraturan Menteri Kesehatan Nomor 30 Tahun 2014 tentang standar pelayanan kefarmasian di Puskesmas penyimpanan adalah suatu kegiatan menyimpan dan memelihara dengan cara menempatkan obat-obatan yang diterima pada tempat yang dinilai aman dari pencurian serta gangguan fisik yang dapat merusak mutu obat.

Tata cara penyimpanan obat menurut Peraturan Menteri Kesehatan Nomor 73 Tahun 2016 :

1. Obat/ bahan obat harus disimpan dalam wadah asli pabrik. Dalam hal pengecualian atau darurat dimana isi dipindahkan pada wadah lain, maka harus dicegah terjadinya kontaminasi dan harus ditulis informasi yang jelas pada wadah baru. Wadah sekurang kurangnya memuat nama obat, nomor batch dan tanggal kadarluasa.

[a] Semua obat/ bahan obat harus disimpan pada kondisi yang sesuai sehingga terjamin keamanan dan stabilitasnya.[b]Tempat penyimpanan obat tidak dipergunakan untuk penyimpanan barang lainya yang menyebabkan kontaminasi.[c]Sistem penyimpanan dilakukan dengan mempertahankan bentuk sediaan dan kelas terapi obat serta disusun secara alfabetis.

Pengeluaran obat harus menggunakan sistem FEFO (First Expire First Out) dan FIFO (First In First Out).

\section{Standar Penyimpanan Obat}

Dalam upaya pengobatan suatu penyakit, perlu diberikan beberapa jenis obat yang saling berbeda baik bentuk sediaannya maupun kemasannya, hal ini perlu dipikirkan cara menyimpan obat. Bila cara penyimpanan obat tidak memenuhi persyaratan cara menyimpan obat yang benar, maka akan terjadi perubahan sifat obat tersebut, sampai terjadi kerusakan obat (BNPB, 20008)

Menurut Direktorat Jendral Bina Kefarmasian dan Alat Kesehatan tentang Materi pelatihan peningkatan pengetahuan dan keterampilan memilih obat bagi Tenaga Kesehatan tahun 2008 cara penyimpanan obat ialah sebagai berikut : 


\section{Tablet dan kapsul}

Jangan menyimpan tablet atau kapsul ditempat panas dan atau lembab.

\section{Sediaan obat cair}

Obat dalam bentuk cair jangan disimpan didalam lemari pendingin (freezer) agar tidak beku kecuali disebutkan pada kemasaan obat.

\section{Sediaan obat vagina dan ovula}

Sediaan obat untuk vagina dan anus (ovula dan suppositoria) disimpan dalam lemari es karena dalam suhu kamar akan mencair.

\section{Sediaan Aerosol/Spray}

Sediaan obat jangan disimpan di tempat yang bersuhu tinggi karena dapat menyebabkan ledakan.

\section{Standar Penyimpanan Alat Kesehatan}

Intstrumen dapat berkarat akibat daari kondisikondisi penyimpanan yang kurang baik. Untuk mencegah hal tersebut instrumen harus disimpan di tempat yang kering dan bebas debu. Perubahan temperatur yang flukuati harus dihindari untuk mencegah akumulasi embun (air kondensasi) pada permukaan instrumen (Pemeliharaan Instrumen yang Tepat, 2005).

\section{Gudang}

Gudang di Apotek Restu Farma Merupakan tempat penyimpanan, obat, alat kesehatan, dan perbekalan kesehatan lainnya. Pergudangan adalah segala upaya pengelolaan gudang yang meliputi penerimaan, penyimpanan, pemeliharaan, pendistribusian, pengendalian dan pemusnahan agar kualitas dan kuantitas tetap terjamin (BNPB, 2009).

\section{Manfaat Pergudangan yang baik :}

a. Terjaganya kualitas dan kuantitas sediaan farmasi.

b. Tertatanya Perbekalan Kesehatan.

c. Peningkatan pelayanan pendistribusian.

d. Tersedianya data dan informasi yang lebih akurat, aktual, dan dapat di pertanggung jawabkan.

e. Kemudahan dalam pengendalian Apotek pengawasan.

Apotek adalah sarana pelayanan kefarmasian tempat dilakukan praktik kefarmasian yang meliputi pembuatan termasuk pengendalian mutu sediaan farmasi, pengamanan, pengadaan, penyimpnan dan pendistribusian obat, pelayanan atas resep dokter, pelayanan informasi obat serta pengembangan obat, bahan obat dan obat tradisional yang harus dilakukan oleh Apoteker(DepkesRI,2000).

Menurut Kamus Besar Bahasa Indonesia, "Apotek". adalah toko tempat meramu dan menjual obat berdasarkan resep dokter serta memperdagangkan barang medis. Pengertian Apotek menurut Keputusan Menteri Kesehatan Republik Indonesia Nomor 1332/MenKes/SK/X/2002, Apotek adalah suatu tempat tertentu, tempat dilakukan pekerjaan kefarmasian penyaluran perbekalan farmasi kepada masyarakat.Pekerjaan Kefarmasian yang dimaksud diantaranya pengadan obat, penyimpanan obat, pembuatan sediaan obat, peracikan, penyaluran, dan penyerahan perbekalan farmasi serta memberikan informasi kepada masyarakat mengenai pembekalan kefarmasian yang terdiri dari obat, bahan obat, obat tradisional, alat kesehatan dan kosmetik.

Apotek Restu Farma berada di Jl. Raya Leuwiliang No.21 A Pasar Lama Ds. Leuwiliang, Kec.

Leuwiliang.Kab Bogor. Didirikan pada bulang oktober tahun 2010 oleh bapak Robbi Saputra,Apotek Restu Farma memiliki satu Apoteker penanggung, dan dua asisten Apoteker. Tujuan dari mendirikan Apotek karena melihat peluang dimana masih belum ada Apotek di daerah Pasar Lama Leuwiliang.

\section{Desain Penelitian}

Penelitian ini termasuk jenis penelitian observasi dengan cara mengamati objek dan hasilnya dipaparkan secara deskriptif, dan pengambilan data dilakukan secara dokumentasi dan wawacara pada pengelola dan penanggung jawab Apotek Restu Farma.

\section{Populasi dan Sampel}

a. Populasi : Semua Produk yang berada di Apotek Restu Farma (Obat, Alat Kesehatan, PKRT, Susu, dan parfum)

b. Sampel : Semua jenis Obat dan Alat Kesehatan yang berada di Apotek Restu Farma (Obat Bebas, Obat Bebas Terbatas, Obat Keras, Obat Tradisional, dan Alat Kesehatan) 
Kerangka Konsep

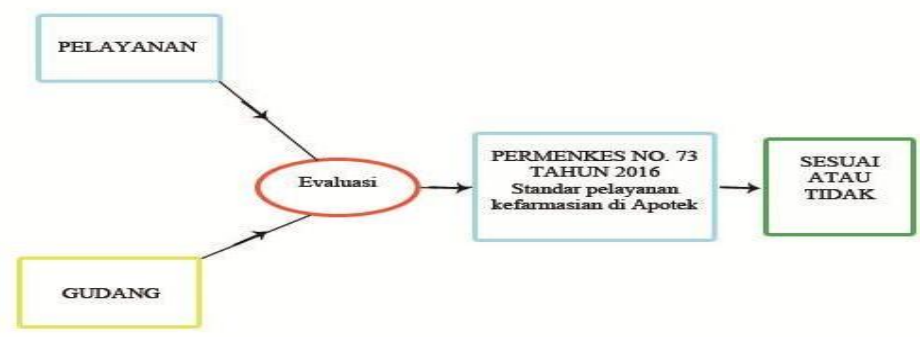

Gambar 1. Kerangka konsep penyimpanan obat dan alat kesehatan

Penyimpanan obat dan alat kesehatan yang berada di Apotek Restu Farma di evaluasi dengan menyesuaikan dengan Peraturan Menteri Kesehatan No. 73 Tahun 2016 dengan melihat langsung kondisi penyimpanan dan mewawancara pegawai Apotek Restu Farma. Kemudian dibandingkan dengan peraturan yang ada apakah kondisi penyimpanan Apotek Restu Farma sesuai dengan peraturan yang ada atau tidak.

\section{Cara Kerja}

\section{Prosedur Penelitian}

Pengumpulan data dilakukan dengan caramelakukan pengamatan pada tempat menyimpan obat dan alat kesehatan di Apotek Restu Farma, serta wawancara kepada pengelola dan penanggung jawab Apotek. Dilakukanya evaluasi setiap obat dan alat kesehatan dan dikelompokan sehingga dapat disesuaikan dengan Peraturan Mentri Kesehatan No.73 Tahun 20216 yang mencakup:

1. Obat/ bahan Obat harus disimpan dalam wadah asli pabrik. Dalam hal pengecualian atau darurat dimana isi dipindahkan pada wadah lain, maka harus dicegah terjadinya kontaminasi dan harus ditulis informasi yang jelas pada wadah baru. Wadah sekurang - kurangnya memuat nama obat, nomor batch dan tanggal kadarluasa.
2. Semua Obat/ bahan Obat harus disimpan pada kondisi yang sesuai sehingga terjamin keamanan dan stabilitasnya.

3. Tempat penyimpanan obat tidak diperguankan untuk penyimpanan barang lainya yang menyebabkan kontaminasi.

4. Sistem penyimpanan dilakukan dengan mempertahankan bentuk sediaan dan kelas terapi Obat serta disusun secara alfabetis.

Pengeluaran obat harus menggunakan sistem FEFO (First Expire First Out) dan FIFO (First In First Out).

\section{Teknik Pengumpulan Data}

Data diperoleh dari hasil wawancara kepada pengelola dan penanggung jawab Apotek, data juga diperoleh dengan pengamatan langsung dari cara penyimpanan obat di Apotek Restu Farma secara tertulis dan dibuat dokumentasi (foto).

\section{Analisis Data}

Data yang didapat dianalisa secara deskriptif dengan melihat keadaan tempat menyimpan obat dan alat kesehatan. Hasil akan disajikan secara deskriptif dalam bentuk tabel dan diagram. 


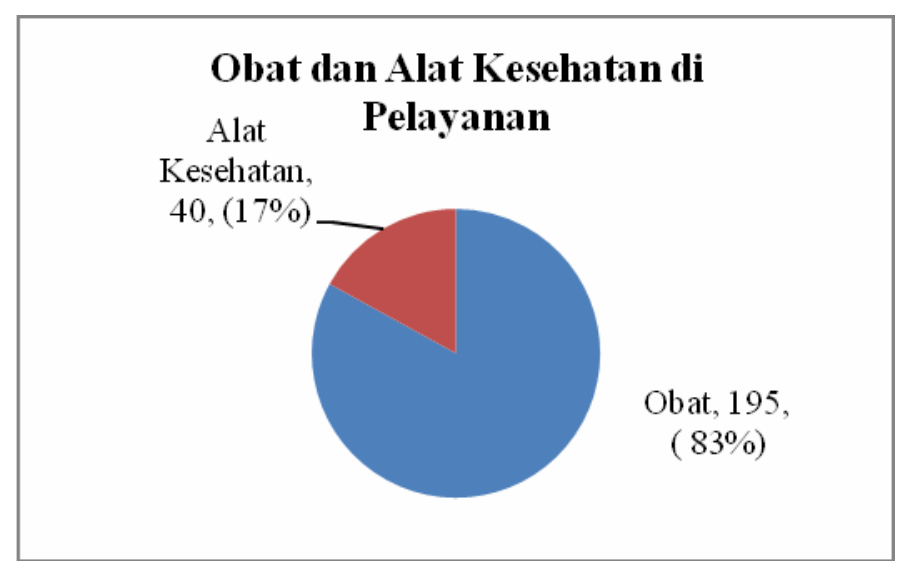

Gambar 2. Obat dan Alat Kesehatan di Ruang Pelayanan Restu Farma

Gambaran Persentase Obat dan Alat Obat - obatan yang ada di Apotek Restu Farma Kesehatan di Pelayanan di golongkan ke beberapa jenis obat

Tata letak penyimpanan obat dan alat kesehatan diantaranya ; obat bebas, obat bebas terbatas, obat keras dan obat tradisional. Kemudian di di pelayanan merupakan hal yang penting sesuaikan dengan Peraturan Menteri Kesehatan karena di Apotek Restu Farma obat dan alat kesehatan cukup banyak mencapai total 235 No. 73 Tahun 2016 tentang standar pelayanan jenis obat dan alat kesehatan.

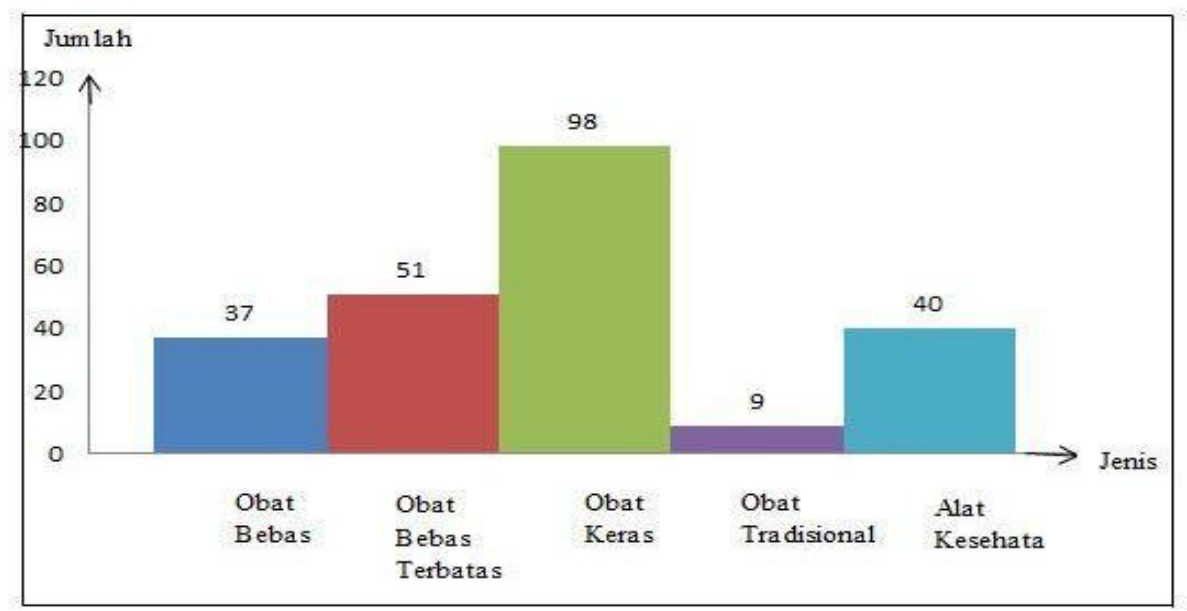

Gambar 3. Total jenis Obat dan Alat Kesehatan di ruang Pelayanan

Evaluasi Penyimpanan Obat dan AlatKesehatan di Pelayanan Berdasarkan Jenis Obat

Obat Bebas

Tabel 1. Persentase Kesesuaian Penyimpanan Obat Bebas

\begin{tabular}{clcc}
\hline No & $\begin{array}{c}\text { Peraturan Permenkes No 73 Tahun } \\
\mathbf{2 0 1 6}\end{array}$ & $\begin{array}{c}\text { Total jenis Obat yang } \\
\text { memenuhi peraturan }\end{array}$ & $\begin{array}{c}\text { Persentase N } \\
\mathbf{= 3 7}\end{array}$ \\
\hline $\mathbf{1}$ & Disimpan sesuai dengan kelas terapinya & 36 & $97 \%$ \\
\hline $\mathbf{2}$ & Disusun secara alfabetis & 0 & $0 \%$ \\
\hline $\mathbf{3}$ & Disimpan dalam wadah asli & 37 & $100 \%$
\end{tabular}


15|Muhammad Afqary et al. (Evaluasi Penyimpanan Obat danAlat ...)

\begin{tabular}{cllcc}
\hline $\mathbf{4}$ & $\begin{array}{l}\text { Terdapat } \\
\text { kemasan }\end{array}$ & & 37 & $100 \%$ \\
\hline $\mathbf{5}$ & No Batch & 37 & $100 \%$ \\
\hline $\mathbf{6}$ & $\begin{array}{l}\text { Disimpan } \\
\text { stabilnya }\end{array}$ & 37 & $100 \%$ \\
& sesuai $\quad$ dengan tempat & 37 & $100 \%$ \\
\hline $\mathbf{7}$ & Tidak dicampur dengan bahan lain yang & & $100 \%$ \\
& menyebabkan kontaminasi & 37 & $87.12 \%$ \\
\hline
\end{tabular}

Dilihat tabel diatas, kesesuaian penyimpanan dengan Peraturan Menteri Kesehatan Nomor 73 Tahun 2016 tentang standar pelayanan kefarmasian di Apotek dengan hasil; Disimpan dalam wadah asli, terdapat tanggal kadaluarsa, No. batch, disimpan sesuai tempat stabilnya, tidak dicampur dengan bahan lain yang menyebabkan kontaminasi, dan sistem pengeluaran obat menggunakan FIFO dan FEFO sudah $100 \%$. Kemudian disimpan sesuai dengan kelas terapi sudah $97 \%$ hal ini dikarenakan terbatasnya rak penyimpanan sehingga ditempatkan di tempat yang masih bisa disimpan. Hanya disusun secara alfabetis saja yang belum dilakukan hal ini di karenakan ketersediaan stok obat di gudang Apotek Restu Farma tidak selalu dengan merek yang sama, namu penyimpanan obat di pisahkan dalam bentuk sediaan ( tablet dan sirup) . Hasil rata rata persentase penyimpanan obat bebas di ruang pelayanan mencapai $86.75 \%$.

\section{Obat Bebas Terbatas}

Tabel 2. Persentase Kesesuaian Penyimpanan Obat Bebas Terbatas

\begin{tabular}{llcc}
\hline No & \multicolumn{1}{c}{ Peraturan Permenkes No 73 Tahun } & Total jenis Obat yang & Persentase \\
& \multicolumn{1}{c}{ memenuhi peraturan } & N =51 \\
\hline $\mathbf{1}$ & Disimpan sesuai dengan kelas terapinya & 41 & $80 \%$ \\
\hline $\mathbf{2}$ & Disusun secara alfabetis & 51 & $100 \%$ \\
\hline $\mathbf{3}$ & Disimpan dalam wadah asli & 51 & $100 \%$ \\
\hline $\mathbf{4}$ & Terdapat tanggal kadaluarsa pada kemasan & 51 & $100 \%$ \\
\hline $\mathbf{5}$ & No Batch & 51 & $100 \%$ \\
\hline $\mathbf{6}$ & Disimpan sesuai dengan tempat stabilnya & 51 & $100 \%$ \\
\hline $\mathbf{7}$ & Tidak dicampur dengan bahan lain yang & & $100 \%$ \\
\hline & menyebabkan kontaminasi & 51 & $85 \%$ \\
\hline
\end{tabular}


Pada penyimpanan obat bebas terbatas hampir semua standar penyimpanan sudah di lakukan.Disimpan sesuai dengan kelas terapi mencapai $80 \%$, hanya beberapa obat tidak seperti disimpan sesuai dengan kelas terapinya dikarenakan terbatasnya lemari penyimpanan obat.Sehingga diletakan ditempat yang bukan kelas terapinya. Penyimpanan secara alfabetis

masih belum dilakukan dikarenakan ketersediaan stok obat di gudang Apotek Restu Farma tidak selalu dengan merek yang sama, namu penyimpanan obat di pisahkan dalam bentuk sediaan ( tablet dan sirup). Hasil rata rata persentase penyimpanan obat bebas terbatas di ruang pelayanan mencapai $85 \%$.

\section{Obat Keras}

Tabel 3. Persentase Kesesuaian Penyimpanan Obat Keras

\begin{tabular}{llccc}
\hline No & \multicolumn{1}{c}{$\begin{array}{c}\text { Peraturan Permenkes No 73 } \\
\text { Tahun 2016 }\end{array}$} & $\begin{array}{c}\text { Total jenis Obat yang } \\
\text { memenuhi peraturan }\end{array}$ & $\begin{array}{c}\text { Persentase } \\
\text { N =98 }\end{array}$ \\
\hline $\mathbf{1}$ & $\begin{array}{l}\text { Disimpan } \\
\text { terapinya }\end{array}$ & sesuai dengan & kelas & 97 \\
\hline $\mathbf{2}$ & Disusun secara alfabetis & 0 & $0 \%$ \\
\hline $\mathbf{3}$ & Disimpan dalam wadah asli & 98 & $100 \%$ \\
\hline $\mathbf{4}$ & $\begin{array}{l}\text { Terdapat tanggal kadaluarsa pada } \\
\text { kemasan }\end{array}$ & 98 & $100 \%$ \\
\hline $\mathbf{5}$ & No Batch & 98 & $97 \%$ \\
\hline $\mathbf{6}$ & $\begin{array}{l}\text { Disimpan } \\
\text { stabilnya }\end{array}$ & 96 & $96 \%$ \\
\hline $\mathbf{7}$ & Tidak dicampur dengan bahan lain & 95 & $100 \%$ \\
& yang menyebabkan kontaminasi & 98 & $86.37 \%$ \\
\hline $\mathbf{8}$ & FIFO/ FEFO & & \\
\hline Rata-Rata Persentase Untuk Penyimpanan Obat Bebas Keras & \\
\hline
\end{tabular}

Hasil dari obat keras yang sudah sesuai dengan standar penyimpanan adalah Disimpan dalam wadah asli, Terdapat tanggal kadaluarsa, terdapat nomor batch dan sistem FIFO/ FEFO sudah dilakukan dengan hasil persentase $100 \%$, disimpan sesuai dengan kelas terapinya $98 \%$ hanya lansoprazol yang tidak disimpan sesuai dengan kelas terapinya dikarenakan jumlahnya sedikit sehingga ditempatkan ditempat yang tidak memakan banyak ruang. Disimpan sesuai dengan tempat stabilnya 97\% Phenytoin dan Neo K disimpan dalam lemari pendingin yang seharusnya disimpan pada suhu ruangan. Tidak dicampur dengan bahan lain yang menyebabkan kontaminasi $96 \%$ pada lemari pendingin diletakan makanan dan minuman, hal ini dikhawairkan menyebabkan kontaminasi pada obat. Penyimpanan secara alfabetis masih belum dilakukan dikarenakan ketersediaan stok obat di gudang Apotek Restu Farma tidak selalu dengan merek yang sama, namu penyimpanan obat di pisahkan dalam bentuk sediaan ( tablet, sirup, infus, dan injeksi) Hasil rata - rata persentase penyimpanan obat keras di ruang pelayanan mencapai $86.37 \%$. 
17|Muhammad Afqary etal. (Evaluasi Penyimpanan Obat dan Alat ...)

Obat Tradisonal

Tabel 4. Persentase Kesesuaian Penyimpanan Obat Tradisional

\begin{tabular}{llcc}
\hline No & \multicolumn{1}{c}{$\begin{array}{c}\text { Peraturan Permenkes No 73 Tahun } \\
\text { 2016 }\end{array}$} & $\begin{array}{c}\text { Total jenis Obat yang } \\
\text { memenuhi peraturan }\end{array}$ & $\begin{array}{c}\text { Persentase } \\
\text { N =9 }\end{array}$ \\
\hline $\mathbf{2}$ & Disimpan sesuai dengan kelas terapinya & 9 & $100 \%$ \\
\hline $\mathbf{3}$ & Disusun secara alfabetis & 0 & $0 \%$ \\
\hline $\mathbf{4}$ & Terdapat tanggal kadaluarsa pada & 9 & $100 \%$ \\
& kemasan & 9 & $100 \%$ \\
\hline $\mathbf{5}$ & No Batch & 9 & $100 \%$ \\
\hline $\mathbf{6}$ & Disimpan sesuai dengan tempat stabilnya & 9 & $100 \%$ \\
\hline $\mathbf{7}$ & Tidak dicampur dengan bahan lain yang & 9 & $100 \%$ \\
& menyebabkan kontaminasi & 9 & $87.5 \%$ \\
\hline $\mathbf{8}$ & FIFO/ FEFO & & \\
\hline & Rata-Rata Persentase Untuk Penyimpanan Obat Tradisional \\
\hline
\end{tabular}

Pada penyimpanan obat tradisional hampir semua sudah dilakukan hanya saja masih belum menyimpan secara alfabetis dikarenakan jumlahnya sedikit sehingga lebih efektif disimpan berdasarkan kelas terapinya, namun

penyimpanan obat di pisahkan dalam bentuk sediaan ( tablet dan sirup). Hasil rata - rata persentase penyimpanan obat tradisional di ruang pelayanan mencapai $87.5 \%$.

\section{Alat Kesehatan}

Tabel 5. Persentase Kesesuaian Penyimpanan Alat Kesehatan

\begin{tabular}{clcc}
\hline No & Peraturan Permenkes No 73 Tahun 2016 & $\begin{array}{c}\text { Total jenis Obat yang } \\
\text { memenuhi peraturan }\end{array}$ & $\begin{array}{c}\text { Persentase N } \\
\mathbf{4}\end{array}$ \\
\hline $\mathbf{1}$ & Disimpan sesuai dengan kelas terapinya & 40 & $100 \%$ \\
\hline $\mathbf{2}$ & Disusun secara alfabetis & 0 & $0 \%$ \\
\hline $\mathbf{3}$ & Disimpan dalam wadah asli & 40 & $100 \%$ \\
\hline $\mathbf{4}$ & Terdapat tanggal kadaluarsa pada kemasan & 25 & $63 \%$ \\
\hline $\mathbf{5}$ & No Batch & 27 & $67 \%$ \\
\hline $\mathbf{6}$ & Disimpan sesuai dengan tempat stabilnya & 38 & $100 \%$ \\
\hline $\mathbf{7}$ & Tidak dicampur dengan bahan lain yang & 40 & $100 \%$ \\
& menyebabkan kontaminasi & 40 & $78.125 \%$ \\
\hline $\mathbf{8}$ & FIFO/ FEFO & & \\
\hline & Total Persentase Penyimpanan Alat Kesehatan & \\
\hline
\end{tabular}

Hasil data alat kesehatan seperti disimpan sesuai dengan kelas terapinya, disimpan dalam wadah asli, tidak dicampur dengan bahan lain yang menyebabkan kontaminasi, dan sistem 
18|Muhammad Afqary etal. (Evaluasi Penyimpanan Obat danAlat ...)

pengeluaran menggunakan FIFO/FEFO sudah sesuai. Terdapat tanggal kadaluarsa pada kemasan $63 \%$ dan nomor batch $67 \%$ hal ini dikarenakan ada beberapa alat kesehatan yang dapat di pakai berulang kali hanya dibungkus plastik putih sehingga tidak ada nomor batch dan tanggal kadaluarsa.Disimpan sesuai dengan kelas terapinya $95 \%$ hal ini dikarenakan ada beberapa alat kesehatan yang berukuran besar seperti kasur pasien yang tidak bisa di letakan di dalam ruangan sehingga diletakan di luar, ini dikhawatirkan terkena hujan dan rawan pencurian.Masih belum di simpan secara alfabetis karena cukup sulit dikaerenakan ada alat kesehatan yang tidak ada namanya sehingga lebih efektif diletakan berdasarkan kelast terapi.

\section{Rata - Rata Penyimpanan Obat dan Alat Kesehatan di Ruang Pelayanan}

Table 6 Persentase penyimpanan obat dan alat kesehatan di ruang pelayanan

\begin{tabular}{clc}
\hline No & Jenis Obat & Persentase \\
\hline $\mathbf{1}$ & Obat Bebas & $87.12 \%$ \\
\hline $\mathbf{2}$ & Obat Bebas Terbatas & $85 \%$ \\
\hline $\mathbf{3}$ & Obat Keras & $86.37 \%$ \\
\hline $\mathbf{4}$ & Obat Tradisional & $87.5 \%$ \\
\hline $\mathbf{5}$ & Alat Kesehatan & $78.125 \%$ \\
\hline & & \\
\hline
\end{tabular}

Hasil penyimpanan obat dan alat kesehatan diruang pelayanan yang disesuaikan dengan Peraturan Menteri Kesehatan Nomor 73 Tahun 20016 tentang standar pelayanan kefarmasian di Apotek secara keseluruhan sudah sesuai dan hasil rata - rata persentase penyimpanan adalah $85 \%$.

\section{Evaluasi Penyimpanan Obat dan Alat Kesehatan di Gudang}

Gudang merupakan tempat pemberhentian sementara barang sebelum dialirkan, dan berfungsi mendekatkan barang kepeda pemakai sehingga menjamin kelancaran permintaan dan keamanan persediaan (Direktorat Bina Marga, 1999). Pergudangan adalah segala upaya pengelolaan gudang yang meliputi penerimaan, penyimpanan, pemeliharaan, pendistribusian, pengendalian dan pemusnahan agar kualitas dan kuantitas tetap terjamin (BNPB, 2009).

Apotek Restu Farma memiliki gudang untuk menyimpan obat dan alat kesehatan. pengelolaan penyimpanan obat dan alat kesehatan di gudang Apotek Restu Farma disesuaikan dengan Peraturan Menteri Kesehatan No.73 Tahun 2016 tentang standar pelayanan kefarmasian di Apotek dengan hasil sebagai berikut :

Table 7. Data penyimpanan di Gudang

\begin{tabular}{lllc}
\hline No & Peraturan Permenkes No 73 Tahun 2016 & \multicolumn{2}{c}{ Kesesuaian } \\
\cline { 3 - 4 } & & Sudah Dilakukan & Belum Dilakukan \\
\hline $\mathbf{1}$ & Disimpan sesuai dengan kelas terapinya & $\checkmark$ & $\checkmark$ \\
\hline $\mathbf{2}$ & Disusun secara alfabetis & & \\
\hline $\mathbf{3}$ & Disimpan dalam wadah asli & $\checkmark$
\end{tabular}


4 Terdapat tanggal kadaluarsa pada kemasan

5 No Batch

6 Disimpan sesuai dengan tempat stabilnya

7 Tidak dicampur dengan bahan lain yang

menyebabkan kontaminasi

8 FIFO/ FEFO

Persentase Penyimpanan Obat dan Alat Kesehatan di Gudang

$75 \%$

Dari data diatas Apotek Restu Farma sudah menerapkan tata cara penyimpanan sesuai dengan Peraturan Menteri Kesehatan No.73 Tahun 2016 tentang standar pelayanan kefarmasian di Apotek mecapai persentase $75 \%$, gudang hanya masih belum menyimpan sesuai dengan alfabetis dikarenakan obat dari PBF (Pedagang Besar Farmasi) terkadang kehabisan stok sehingga merek yang ada di Apotek Restu Farma selalu berbeda yang menyebabkan obat tidak disusun secara alfabetis, namun di gudang Apotek Restu Farma dipisahkan berdasarkan bentuk sediaan ( tablet, sirup, infus, dan injeksi) Kemudian gudang Apotek Restu Farma masih dicampur dengan benda lain seperti banner, pintu bekas, dan benda lainya sehingga dikhawatirkan menyebabkan kontaminasi.

\section{KESIMPULAN}

1. Obat dan alat kesehatan yang ada di Apotek Restu Farma berjumlah 83\% obat, dan $17 \%$ alat kesehatan. Distribusi jenis obat yang terbanyak adalah obat keras 97 jenis dari 195 total obat.

2 Penyimpanan obat dan alat kesehatan di ruang pelayanan sudah sesuai dengan Peraturan Menteri Kesehatan Nomor 73 Tahun 2016 tentang standar pelayanan kefarmasian di Apotek dengan hasil persentase $85 \%$

3. Penyimpanan obat dan alat kesehatan di gudang sudah sesuai dengan Peraturan Menteri Kesehatan Nomor 73 Tahun 2016 tentang standar pelayanan kefarmasian di Apotek dengan hasil persentase $75 \%$

4. Penyimpanan obat di ruang pelayanan atau di gudang tidak disusun secaraalfabetis tetapi di dipisahkan berdasarkan bentuk sediaan (tablet, sirup, infus, dan injeksi)

\section{SARAN}

Berdasarkan hasil Karya Tulis Ilmiah (KTI) di Apotek Restu Farma Bogor, saya ingin memberikan saran yang membangun demi kemajuan Apotek Restu Farma, yaitu sebagai berikut:

1. Sebaiknya Apotek Restu Farma lebih mentata obat secara alfabetis baik di ruang pelayanan maupun gudang agar obat atau alat kesehatan lebih mudah dicari.

2. Sebaiknya di lemari pendingin dikhususkan hanya untuk menyimpan obat - obatan saja dan tidak dicampur dengan makananan atau minuman.

3. Sebaiknya alat kesehatan yang berukuran besar seperti kursi roda dan stand infus diletakan di dalam ruangan agar mudah diawasi dan aman dari pencurian.

4. Sebaiknya jika penyimpanan di gudang obat dan alat kesehatan dilokalisir dengan baik maka akan mempermudah untuk mencari obat dan alat kesehatan.

\section{DAFTAR PUSTAKA}

[1]. Ahmad, Sabri. 2007. "Strategi Belajar Mangajar Mikro Teacing". Ciputat : Quatum Teacing.

[2]. Binfar.2008.Direktorat Jendral Bina Kefarmasian dan Alat Keshatan 2008 "Modul TOT Pelayanan Kefarmasiandi Puskesmas". Jakarta: Direktur Bina Farmasi komunitas dan Klinik.

[3]. BNPB.2009.Peraturan Kepala Badan Nasional Penanggulangan Bencana No. 6 Tahun 2009 "Pedoman Pegudangan”. Jakarta: BNPB.

[4]. Departemen Pendidikan dan Kebudayaan, Dikti, (1978), Evaluasi, No. 45, Jakarta 
[5]. Kemkes RI.2002.Keputusan Menteri Kesehatan Republik Indonesia No.1332/MENKES/SK/X/2002 tentang"Ketentuan cara pemberian izin Apotek". Jakarta: Departemen Kesehatan RI..

[5]. Kemkes RI.2011.Keputusan Menteri Kesehatan Republik Indonesia No.059/MENKES/SK/II/2011 tentang"Pedoman Penggolongan Obat dan Perbekalan Kesehatan pada penangggulangan Bencana”. Jakarta: Departemen Kesehatan RI..

[6]. Permenkes RI.2016.Peraturan Menteri Kesehatan Republik Indonesia No. 30 Tahun 2016 tentang "Standar Pelayanan Kefarmasian di Puskesmas". Jakarta: Departemen Kesehatan RI.

[7]. Permenkes RI.2016.Peraturan Menteri Kesehatan Republik Indonesia No. 73 Tahun 2016 tentang "Standar Pelayanan di ". Jakarta: Departemen Kesehatan RI

[8]. Umar, Husein. 2002. "Evaluasi Kinerja Perusahaan". Jakarta : Gramedia Pustaka Utama.

[9]. Paluningtyas, Retno. 2014. "Analisis system penyimpanan obat digudang farmasi rumah sakit mulya tanggerang tahun 2014".

[10]. Universitas Islam Negeri Syarif Hidayatullah.

[11]. Rustyanda, Adella. 2017. "Evaluasi penyimpanan obat digudang Klinik Resmien II Pelopor”. STTIF : Bogor.

[12]. Sukmajati, Monica. 2007. "Pelayanan standar kefarmasian di Apotek berdasarkan Kepmenkes R.I. Nomor 1027/Menkes/SK/IX/2004/

di Yogyakarta". Universitas Sanata Dharma : Yogyakarta 